\title{
ANALYSIS OF THE EFFECTIVENESS OF THE FUNCTIONAL ORGANIZATIONAL MODEL FOR KNOWN PROPHYLAXIS OF CHRONIC NONINFECTIOUS DISEASES BASED ON THE ASSESSMENT OF THE QUALITY OF LIFE OF PATIENTS AT THE MEDICAL INSTITUTION
}

D0I: $10.36740 /$ WLek202103207

\author{
Dmytro D. Dyachuk, Volodymyr A. Gandzyuk, Oleg L. Zyukov \\ STATE INSTITUTION OF SCIENCE "RESEARCH AND PRACTICAL CENTER OF PREVENTIVE AND CLINICAL MEDICINE"STATE ADMINISTRATIVE DEPARTMENT, \\ KYIV, UKRAINE
}

\begin{abstract}
The aim: Study of the indicators of quality of life of patients served by a multidisciplinary health care institution with the functionally-organizational model of coded prevention of chronic noninfectious diseases is implemented.

Materials and methods: To evaluate the effectiveness of the model's use we used the assessment of the dynamics of QL indices, which was assessed according to the EUROHISQ0L 8-item index methodology among 376 patients aged over 18 years.

Results: Most of the respondents (61.4\%) were dissatisfied to varying degrees with their state of health and, on average, evaluated their QL (56.1\%). 3The overall assessment of the quality of life of the surveyed population was on a 20-point scale of 13.5 (3.19) points in 2017 before the introduction of the program of managed prevention of CNCDs and 14.6 (3.48) points after its three-year operation, with an increase integrated indicator on average by 1.1 ( $95 \% \mathrm{Cl} 0.59-1.60)$ points ( $\mathrm{p}<0.001)$. Among the areas of $\mathrm{Q} 0 \mathrm{~L}$ assessment, the assessments in the physical sphere and the environment increased at most $(p<0.05)$. It is determined that the overall level of $Q 0 \mathrm{~L} \mathrm{of} \mathrm{patients} \mathrm{with} \mathrm{NCDs} \mathrm{is} 40 \%$ due to medical and social factors that can be positively influenced by medical care using a model of managed prevention.

Conclusions: The analysis of changes in the quality of life of patients of multidisciplinary institutions who have risk factors for CNCDs or suffer from chronic non-communicable diseases, showed that the introduction of a functional-organizational model of managed prevention at the health care institution level can improve integrated assessment of QOL and positively affect the overall complex of medical and social factors, including managed risk factors. This indicates the effectiveness of this model of managed prevention at the level of a multidisciplinary health care institution.
\end{abstract}

KEY WORDS: chronic non-communicable diseases (Noncommunicable diseases (NCDs)); quality of life related to health; functional and organizational model; managed prevention

Wiad Lek. 2021;74(3 p.II):603-607

\section{INTRODUCTION}

The fight against chronic non-communicable diseases covers all levels of health care and requires active participation at all levels of health management.

At the global level, among the "Sustainable Development Goals", Goal 3 "Strong health and well-being" stands out, which provides "Ensuring a healthy lifestyle and well-being of people of all ages." Among the top goals of this goal is paragraph 3.4 - "By 2030, reduce by one third premature deaths from non-communicable diseases through prevention and treatment, as well as maintain mental health and well-being." [1].

At the level of the health care facility (HCF), the completeness of the coverage of patients with chronic non-communicable diseases (NCDs) by continuous medical care is crucial. [2].

At present, experts note that progress in fulfilling the commitments to reduce the burden of NCDs has been insufficient at all possible points of influence [3], the issue was particularly acute in the absence of financial investment and resource constraints [4]. The problem became even more acute in the context of the COVID-19 pandemic $[5,6]$.

According to the World Health Organization (WHO), the proportion of deaths from noncommunicable diseases is $71 \%$ in 2018 , which is significantly higher than in 2000 , when it was $40 \%$. It is noted that $85 \%$ of deaths from NCDs were premature. Regarding the profile of Ukraine, according to WHO estimates, despite some positive dynamics of the probability of premature death from non-communicable diseases, death from NCDs is $91 \%$ of all deaths in the country (63\% from cardiovascular disease), and the risk of premature death between $30-70$ years is $25 \%$, while the share of primary care centers in which the stratification of the risk of cardiovascular disease ranges from $25 \%$ to $50 \%[7,8]$. 
It is believed that chronic non-communicable diseases lead to a deterioration in health-related quality of life (HRQoL). However, to date, research has been conducted to determine the factors influencing HRQoL in NCDs and their relationship $[9,10]$.

In addition to studying the predictors of quality of life in patients with non-communicable diseases, the QOL indicator can be used to assess the performance of various parts of the health care system, to monitor the results of medical interventions [11].

Assessments of various aspects of the health care system have become widespread in various countries, including Ukraine. Measurement of activity is most often carried out by measuring the processes and results at different levels, including at the level of the medical institution [10]. However, comprehensive research to assess the effectiveness of the implementation of innovative organizational aspects of medical care in NCDs is lacking, which led to the relevance of the study.

\section{THE AIM}

Study of indicators of quality of life of patients served by a multidisciplinary health care institution, where a functional-organizational model of managed prevention of chronic non-communicable diseases has been introduced.

\section{MATERIALS AND METHODS}

The study was conducted on the basis of the State Institution of Science "Research and Practical Center of Preventive and Clinical Medicine" State Administrative Department, where a functional-organizational model of managed prevention was implemented. To assess the effectiveness of the model, we used the assessment of the dynamics of QOL indicators. The survey was conducted twice in 2017 - before the introduction of the model of managed prevention and in 2020 - after its introduction and operation.

The study involved 376 patients over 18 years of age who were served in the HCF during 2017 - 2020. In the second stage of the study, 342 people were interviewed, which is $9.0 \%$ less than the initial number of patients. It is the results of a survey of patients who were interviewed twice that formed the basis of this publication.

Among the surveyed were $42.4 \%$ men and $57.6 \%$ women, the age of the respondents ranged from 18 to 82 years, the average age was 52.3 (15.5) years $\mathrm{M}(\mathrm{SD})$.

The study of the quality of life of patients was conducted according to the WHO QOL method - 8 (EUROHIS-QOL 8 -item index) which is an abbreviated modification of the WHO QOL questionnaire - 26 (WHOQOL-BREF) and showed satisfactory discriminant validity and is a suitable method for assessing the effectiveness of health care $[12,13]$.

The questionnaire has general questions on the assessment of QOL and questions related to various areas - the physical sphere, the psychological sphere, social relation- ships, the environment (Physical, Psychological, Social relationship, Environment).

The analysis of questions related to the four areas of quality of life included a score of each area on the points of answers to the questionnaire (from 1 to 5 ) and their conversion to values in the range $0-20$. The maximum total score (taking into account the direction of the answers) is the same for all areas. It cannot exceed 20 points and has set interpretation intervals for the assessment of quality of life: the range from 4 to 6 points corresponds to a very poor assessment, from 7 to 10 - bad, 11-13 average, 14-17 - good, and 18-20 - very good [12]. The consequence of such assessment is the ability to quantify the respondent's satisfaction with different aspects of life and get a profile by area.

Information from the anamnestic questionnaires of patients collected during care at SIS RPCPCM was also used. Participation in the survey took place only with the informed consent of patients.

The research materials were processed using the Excel-2010 spreadsheet editor and the software package MedCalc Statistical Software trial version 19.6.4 (MedCalc Software bvba, Ostend, Belgium; https://www.medcalc.org; 2021). Statistical processing of the results was performed using the methods of descriptive and analytical statistics. Assessment of the reliability of differences was performed on the paired Student's $t$ test $(\mathrm{T})$ and the chi-square criterion $\left(\chi^{2}\right)$. Paired and partial correlation coefficients $(r)$ were calculated to assess the relationship between the elements. The level of statistical significance $p<0.05$ is considered critical.

\section{RESULTS}

Interviewed patients evaluate their health differently. Almost every fifth (18.4\%) rated their health at the time of the survey as very good and good, the majority (50.6\%) - as average, almost a quarter (22.8\%) - as poor and very bad. This is primarily due to the fact that respondents were interviewed during a visit to a medical facility, which they carried out for different purposes. The cohort included both patients with acute and chronic illnesses, those who had recovered, and those who had visited a health care facility for a preventive examination.

The majority of respondents (61.4\%) were to varying degrees dissatisfied with their own health, the rest were completely or partially satisfied. These estimates correspond to quality of life assessments. Estimates of the distribution of the overall level of quality of life are distributed approximately in half between negative $(28.7 \%)$ and positive (15.2\%). QOL rated as average - "not bad and not good" - more than half of respondents (56.1\%).

Among the pathological conditions that act as risk factors and for which the examined patients suffer (Fig. 1), arterial hypertension is the most common $-36.17 \%$ (95\% CI 31.31 - 41.03), elevated blood glucose - 30.59\% (95\% CI 25.93 - 35.24), malnutrition - $16.22 \% 95 \%$ CI (12.519.95) and others. 


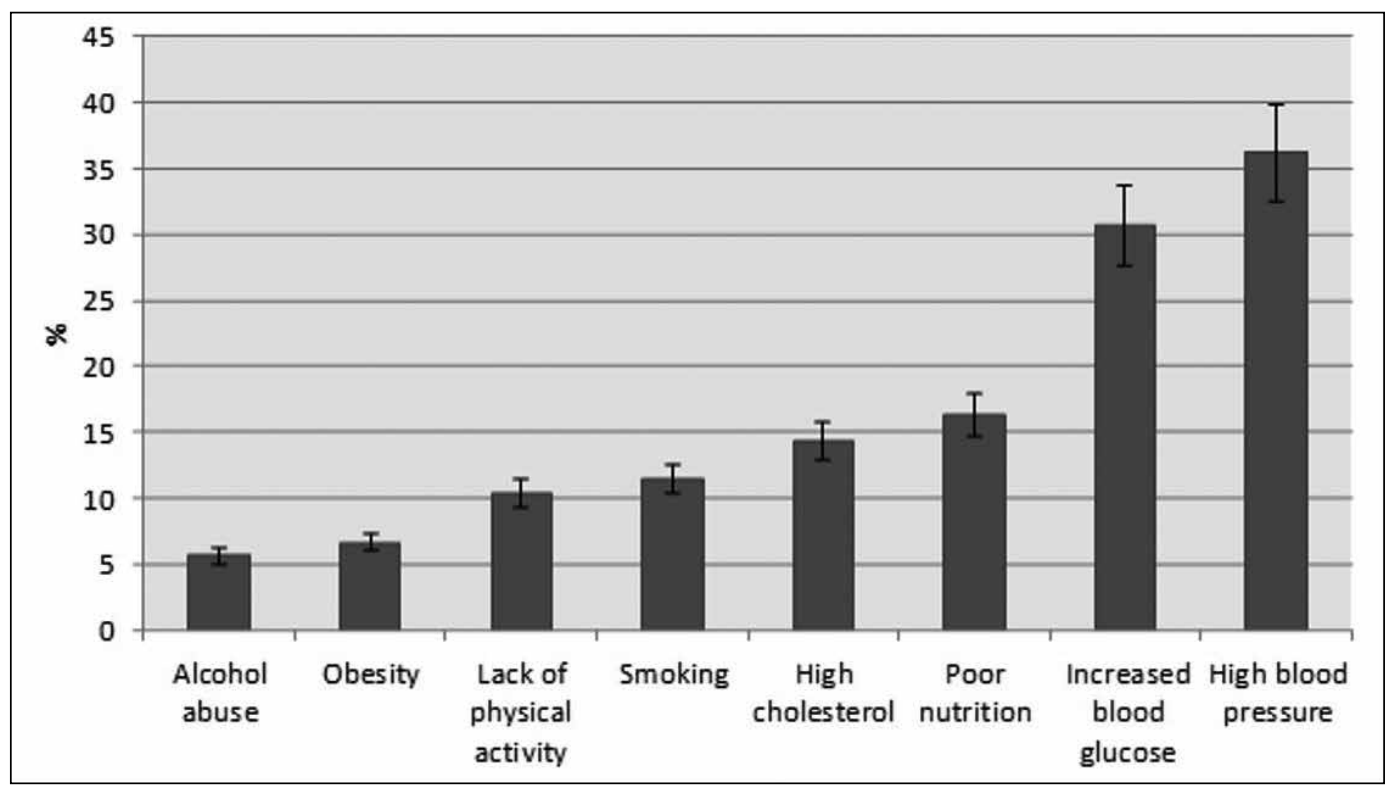

Fig. 1. Frequency of detection of the main risk factors for the development of the most common NCDs in the examined patients (\% and $95 \%(\mathrm{l})$.

Table I. Dynamics of quality of life assessments by areas and in general in the examined patients with NCDs (M (SD) - average points on a 20-point scale EUROHIS-QOL 8-item)

\begin{tabular}{ccccc}
\hline $\begin{array}{c}\text { EUROHIS-QOL 8-item } \\
\text { domains }\end{array}$ & $\begin{array}{c}\text { Before the introduction of the } \\
\text { model of managed prevention } \\
\mathbf{( 2 0 1 7 )}\end{array}$ & $\begin{array}{c}\text { After the introduction of } \\
\text { the model of managed } \\
\text { prevention (2017) }\end{array}$ & $\begin{array}{c}\text { Score difference } \\
\mathbf{M}(\mathbf{9 5 \%} \mathrm{Cl})\end{array}$ & Level \\
\hline Physical & $13,4(3,32)$ & $14,5(4,13)$ & $1,1(0,62-1,58)$ & $<0,001$ \\
\hline Psychological & $13,5(3,17)$ & $14,1(3,68)$ & $0,6(0,08-1,12)$ & 0,023 \\
\hline Social & $14,1(3,31)$ & $14,6(3,12)$ & $0,5(0,02-0,98)$ & 0,043 \\
\hline Environment & $13,6(2,89)$ & $14,1(3,61)$ & $0,8(0,01-0,99)$ & 0,046 \\
\hline EUROHIS-QOL 8-item index & $13,5(3,19)$ & $14,6(3,48)$ & $1,1(0,59-1,60)$ & $<0,001$ \\
\hline
\end{tabular}

The overall assessment of the quality of life of the surveyed population was on a 20 -point scale of NCDs and 14.6 (3.48) points after its three-year operation 0.001) (Table I).

Assessment of quality of life by areas of life showed that the most positive, both in the first and in the second survey, patients assess social relationships, i.e. most respondents do not have problems in the field of personal relationships and social support. To a lesser extent, in the first survey, patients were satisfied with the physical and psychological spheres of life, which indicates a decrease in vital activity, energy and positive emotions in the interviewed population.

Correlation analysis showed that the integrated assessment of QOL of the examined patients is largely formed due to the physical sphere (correlation coefficient $r=0.79$; $p<0.001)$, in the second place - the environment $(r=$ $0.69 ; \mathrm{p}<0.001)$, on the third - psychological sphere $(\mathrm{r}=$ $0,66 ; p<0,001)$ and on the last place on influence of social communications $(\mathrm{r}=0,514 \mathrm{p}<0,001)$. Thus, despite the high assessment of the social sphere, these aspects of life do not have a very large impact on the overall assessment of QOL. And a negative assessment of the environment, which includes elements such as physical security and safety, financial resources, the external environment, as well as elements of medical and social care, has a stronger impact and forms an average low level of QOL patients with NCDs.
The overall quality of life of the examined patients with NCDs is also influenced by various other factors. According to our research, these are such factors as age, marital status, nature of work, health status, nature of medical care, income level. The quality of life of patients with NCDs is more influenced by the state of health: the better the state of health, the higher the overall score of QOL ( $r=0.54, \mathrm{p}$ $<0.01)$. In respondents with very good health, self-esteem, quality of life assessment was $27.2 \%$ higher than the average $(\mathrm{p}=0.031)$. Respondents who rated their health as very poor had a QOL level $17.6 \%$ below average $(\mathrm{p}=0.043)$.

The multiple correlation coefficient, which shows the degree of general influence of the above factors on QOL is $\mathrm{R}=0.6$ and indicates the presence of an average bond strength; the coefficient of determination is $\mathrm{R} 2=0.4$ $(p=0.020)$, which indicates that the overall level of QOL in patients with NCDs by $40 \%$ is due to medical and social factors.

\section{DISCUSSION}

Although all countries are trying to strengthen their health care systems, no significant progress has been made in reducing the burden of chronic noncommunicable diseases $[2,3,7]$. 
During the COVID-19 pandemic, its negative impact on the process of providing medical services at the NCD was revealed, primarily due to the impact on health care financing and resource outflow. In such circumstances, experts call for the elimination of disruptions and continuity of medical care for this group of patients, to use non-standard approaches and tools of e-Health $[5,6]$.

In the context of the COVID-19 epidemic, like most countries, Ukraine is trying to improve the process of integrated multidisciplinary primary health care with NCDs. Of particular importance is the optimization of the organization of medical care for patients with chronic non-communicable diseases at the level of multidisciplinary health care facilities with a coordinating role of the primary care. Coordination and integration play a key role in the organization of patient-centered care with NCDs and the management of results [2].

To achieve positive results in the management of NCDs, it is important to manage risk factors, including modified: high blood pressure, smoking, diabetes, physical activity, obesity, high blood cholesterol, etc. [14]. It should be noted that the prevalence of such risk factors as high blood pressure, high blood sugar, tobacco use and lack of physical activity, our data (Fig. 1), largely correspond to the results of most international studies on NCDs [14] .

Also, an effective strategy is to move to the provision of care for NCDs by larger multidisciplinary teams, in the form of a comprehensive package of preventive services, which expands the possibilities for combating the burden of chronic noncommunicable diseases [2].

Modern strategies for the management of NCDs should be focused on the individual level, when a person is responsible for their health, and HCFs play the role of its provider and regulator in this area [14].

More opportunities for the implementation of integrated management of patients with chronic non-communicable diseases have HCFs that are able to adequately develop the medical route of patients, taking into account the impact on patients of a number of existing risk factors.

A feature of the functional-organizational model of managed prevention, developed and implemented in is the distribution of the population by groups with certain risk factors and their combination, and their further distribution by individual prevention programs, supported by certain distribution of resources available to institutions, which is reflected in the cost of appropriate prevention programs.

The assessment of the quality of life of patients with NCDs, conducted before and after the implementation of the model of managed prevention, showed its effectiveness, as for three years of its operation there was an increase in the integrated indicator by an average of 1.1 (95\% CI 0.59 - 1.60) points Table I). Among the areas of QOL assessment, the highest increase was in the physical field, which describes the health and well-being of patients, and the field of the environment, which also includes elements of medical and social care. It should be noted that the increase in all estimates reached a statistically significant level $(\mathrm{p}<0.05)$.
It was determined that the overall level of QOL in patients with NCDs by $40 \%$ is due to medical and social factors. Recent studies have shown that managed primary care can have a positive effect on the social determinants of NCDs [15]. Thus, adequate care at the primary level using a model of managed prevention can have a positive impact on both medical and social determinants of impact, and integrated indicators of individual health in terms of quality of life.

\section{CONCLUSIONS}

The analysis of changes in the quality of life of patients of multidisciplinary institutions with risk factors for NCDs or suffering from chronic non-communicable diseases showed that the introduction of a functional-organizational model of managed prevention at the HCF level can improve integrated assessment of QOL and positively affect the medical complex. social factors, including managed risk factors. This indicates the effectiveness of this model of managed prevention at the level of a multidisciplinary health care institution.

\section{REFERENCES}

1. Morton S., Pencheon D., Squires N. Sustainable Development Goals (SDGs), and their implementation: A national global framework for health, development and equity needs a systems approach at every level. Br Med Bull. 2017;124(1):81-90. doi: 10.1093/bmb/ldx031.

2. Jakab M., Farrington J., Borgermans L. et al. Health systems respond to NCDs: time for ambition. Copenhagen:WHO Regional Office for Europe. 2018: 278.

3. Nishtar S., Niinistö S., Sirisena M. et al.; Commissioners of the WHO Independent High-Level Commission on NCDs. Time to deliver: report of theWHO Independent High-Level Commission on NCDs. Lancet. 2018 ;392(10143):245-252. doi: 10.1016/50140-6736(18)31258-3.

4. GBD 2019 Universal Health Coverage Collaborators. Measuring universal health coverage based on an index of effective coverage of health services in 204 countries and territories, 1990-2019: a systematic analysis for the Global Burden of Disease Study 2019. Lancet. 2020396(10258):1250-1284. doi: 10.1016/50140-6736(20)30750-9.

5. World Health Organization. The impact of the COVID-19 pandemic on noncommunicable disease resources and services: results of a rapid assessment. Geneva: World Health Organization. 2020: 24.

6. Katzmarzyk P.T., Salbaum J.M., Heymsfield S.B. Obesity, noncommunicable diseases, and COVID-19: A perfect storm. Am J Hum Biol. 2020;32(5):e23484. doi: 10.1002/ajhb.23484.

7. World Health Organization. Noncommunicable Diseases (NCD) Country Profiles. Geneva: World Health Organization. 2018:223.

8. Gruzieva T.S., Diachuk M.D., Inshakova H.V., Zamkevych V.B. Modern demographic trends in Ukraine as a realization of preventional strategies. Wiadomości Lekarskie .2019; 72(10):2033-2039.

9. Van Wilder L., Clays E., Devleesschauwer B. et al. Health-related quality of life in patients with non-communicable disease: study protocol of a cross-sectional survey. BMJ Open. 2020;10(9):e037131. doi: 10.1136/ bmjopen-2020-037131.

10. Zhou T., Guan H., Yao J. et al. The quality of life in Chinese population with chronic non-communicable diseases according to EQ-5D-3L: a systematic review. Qual Life Res. 2018;27(11):2799-2814. doi: 10.1007/ s11136-018-1928-y. 
11. Smith P., Papanicola I. Health system performance comparison: an agenda for policy, information and research. Policy summary 4. UK. Maidenhead: Open University Press; 2013; 26 p.

12. Nosikov A., Gudex C. EUROHIS: developing common instruments for health surveys. Biomedical and health research. 2003;57:204.

13. da Rocha N.S., Power M.J., Bushnell D.M. et al. The EUROHIS-Q0L 8-item index: comparative psychometric properties to its parentWHOQOL-BREF. Value Health. 2012;15(3):449-57. doi: 10.1016/j.jval.2011.11.035.

14. Budreviciute A., DamiatiS., Sabir D.K. et al. Management and Prevention Strategies for Non-communicable Diseases (NCDs) and Their Risk Factors. Front Public Health. 2020;8:574111. doi: 10.3389/fpubh.2020.574111.

15. Allen L.N., Smith R.W., Simmons-Jones F. et al. Addressing social determinants of noncommunicable diseases in primary care: a systematic review. Bull World Health Organ. 2020;98(11):754-765B. doi: 10.2471/BLT.19.248278.

Title of the research topic: "Scientific substantiation of creating a qualitatively new system of prevention of non-communicable diseases and improving the model of managed medical care at the level of multidisciplinary health care institution in the functioning of a single medical information system" (2019-2021, № state registration 0119U001147).

\section{ORCID and contributionship:}

Dmitro D. Dyachuk: 0000-0003-4583-4909 A, D, F

Volodymyr A. Gandziuk: 0000-0001-7066-998X B, C,D

Oleg L. Zyukov: 0000-0001-7954-1448 ${ }^{\text {B, D, E }}$

\section{Conflict of interest:}

The Authors declare no conflict of interest.

\section{CORRESPONDING AUTHOR Oleg L. Zyukov \\ State Scientific Institution "Research and Practical \\ Centre of Preventive and Clinical Medicine \\ 5 Verhnyaya St., 04012 Kyiv, Ukraine \\ tel: +38 (044) 2864700 \\ e-mail: 0.zyukov@gmail.com}

Received: 03.12 .2020

Accepted: 04.03 .2021

A - Work concept and design, B - Data collection and analysis, C - Responsibility for statistical analysis,

D-Writing the article, $\mathbf{E}$-Critical review, $\mathbf{F}$ - Final approval of the article 